\title{
Eco-city indicators: governance challenges
}

\author{
S. Joss, D. Tomozeiu \& R. Cowley \\ Department of Politics and International Relations, \\ University of Westminster, UK
}

\begin{abstract}
According to the most recent (2011) global census of eco-city initiatives, there are currently 178 eco-city initiatives under development, representing a significant mainstreaming of urban sustainability in the last decade. As the number of eco-city initiatives grows, so the question of how to define eco-city indicators and establish standards becomes more pressing. While there are many sustainability standards and certification schemes available for use at building level (e.g. LEED, BREEAM), similar sustainability assessment and endorsement frameworks for the urban level have only recently begun to emerge. This article surveys the current situation by: (i) proposing a conceptual model of urban sustainability indicators from a governance perspective; (ii) presenting the findings of a comparative analysis of the use of urban sustainability indicators in nine eco-city initiatives; and (iii) outlining key challenges for the future development of international urban sustainability standards. It argues that the current situation is marked by a considerable diversity of practice and governance functions, and an ongoing tension between place-specificity and universal applicability as goals of urban sustainability.

Keywords: eco-city, urban sustainability, indicators, standards, certification.
\end{abstract}

\section{Introduction}

The recent global mainstreaming of urban sustainability - through numerous 'eco-city', 'zero/low-carbon city', 'solar city', 'smart city' and 'sustainable city' initiatives - has increased demands for international indicators, standards and related certification schemes (Joss [1]). The effective specification, quantification and monitoring of urban sustainability policies and goals entails the definition of indicators and the establishment of standards. But through what mechanisms should indicators and standards be agreed? Who should be involved in establishing, certifying and monitoring them? And what types of international 
frameworks to guide policy and practice, if any, are conceivable in future? These questions relate less to the technical difficulties of selecting criteria than to policy considerations and governance processes. This becomes particularly apparent within the current context of the globalisation of urban sustainability, characterised by the involvement of a host of international, national and local governmental, non-governmental and private actors operating through various forms of public, private and public-private partnerships.

This article seeks to contribute to this discussion by: (i) considering urban sustainability indicators conceptually from a governance perspective; (ii) comparing the use of indicators in a sample of nine contemporary eco-city initiatives and frameworks; and (iii) elaborating key challenges for future research and policy development in the field.

\section{Urban sustainability indicators as governance processes}

At their most basic, indicators specify in concrete terms what urban sustainability means to a given community (for an overview, see e.g. Hezri and Dovers [2]; Keirstead and Leach [3]; Miller [4]; Munier [5]). They define the elements and goals of urban sustainability - that is, environmental, economic and social sustainable development in relation to urban settings. Given the multifaceted nature of urban sustainability, the wide diversity of indicators in current use is unsurprising, ranging from wastewater recycling to access to open spaces, from greenhouse gas (GHG) emissions to public transport use, and from economic regeneration to well-being. Together, they are often considered as a set, or framework, of indicators in relation to an urban area, and understood as mutually interdependent.

In addition to this definitional work, indicators are also used to monitor performance, by assessing improvements (or deteriorations) over time on defined criteria or targets for particular aspects of sustainability. For example, if an indicator of sustainable transport is defined in terms of access to public transport, the target and assessment might be in relation to the proportion of people being able to reach public transport services within, say, 300 metres of their homes.

The definition of urban sustainability indicators is usually derived from a mixture of scientific-technical analyses, national and local policies and placespecific urban conditions. There is, then, necessarily variation between sets of urban sustainability indicators owing to the respective policy contexts and the nature of the urban areas. In addition, variation can arise from local stakeholder involvement (interest groups, citizens etc), particularly when used to develop 'community indicators'. While this may assure democratic legitimacy, it renders indicators less replicable and open to standardisation.

Increasingly, international and non-governmental actors, such as the World Bank (Eco2 Cities), the United Nations (Urban Indicators Guidelines), and Ecocity Builders (International Ecocity Framework and Standards) are developing and using urban sustainability frameworks, typically in close cooperation with individual cities and private developers. The growth in various public-private governance arrangements has reinforced the need for indicators, 
especially where urban sustainability initiatives operate across and beyond established governmental policy frameworks.

The development and application of urban sustainability indicators should, therefore, not just be considered in technical terms - concerning the scientific evidence base and methodology - but equally in governance terms: which actors are involved in drawing up and using indicators, and how indicators are applied in policy-making and as a social process. From this perspective, indicators can be understood as functioning as strategic instruments to influence policy and as tools for social learning. Under governance, they have a 'soft' function compared with more coercive, regulatory governmental instruments - of mapping, steering, and enhancing communicative deliberation (Hezri and Dovers [2]). They constitute an institutional process of identifying policy, generating knowledge and applying that knowledge in practice. By producing quantifiable information that can be measured and monitored, their function is to underpin policy and decision-making with rationality, control and accountability (Miller [4]). As such, indicators assume particular relevance, as in the case of (urban) sustainability, where significant paradigmatic shifts in the knowledge base and governmental policy are sought, and where decision-making becomes increasingly decentralised and globalised. Within this context, they act as a 'technology of visibility' - that is, they articulate and make visible issues of sustainability not otherwise captured in policy (Miller [4] 425-426).

Arriving at indicators of urban sustainability is one thing; establishing standards - common norms - is quite another. Partly as a result of the multifaceted nature of sustainable development, and partly as a consequence of context-specific variation, there is currently a multitude of indicator lists - "grab bags designed to include everyone's favourite indicators" (Miller [4] 417) - and, in turn, an absence of standardisation. Yet the need for national and international standards can be expected to increase with the global mainstreaming of urban sustainability: policy-makers need to be able to access comparative information and apply consistent measures; developers and practitioners need the certainty of agreed, compatible frameworks, especially as they increasingly operate across various national and cultural contexts; and citizens need tools to hold policymakers and developers to account. The challenge of global standardisation is partly technical in that what is measured and the methods of measuring vary across contexts, and partly political in that there is as yet no umbrella organisation or mechanism that provides a recognised overarching framework.

Instead, as the following analysis shows, the current situation is characterised by a growing number of (partially overlapping) urban sustainability schemes and 'eco-city' frameworks that each, in their own way, define indicators, specify criteria and targets, and set out procedures for designing, developing and implementing urban sustainability initiatives. Some schemes also have a certification, or accreditation, function; examples include BioRegional's One Planet Communities and the Clinton Climate Initiative's Climate+ Development programmes - both illustrating the trend towards non-governmental organisations becoming increasingly involved globally in implementing urban sustainability schemes in co-operation with cities. 
In summary, the analysis of the role of urban sustainability frameworks (encompassing indicators, standards and certification schemes) should relate to questions of both contents - what is defined and quantified - and process and governance - in terms of methodologies, interest groups involved, and resulting policy functions. This article focuses mainly on the latter, given the relative lack of available conceptual and empirical analysis. (Needless to say, further, critical analysis is also required to improve our understanding of the scientific-technical basis of urban sustainability indicators.) As summarised in Table 1, within this governance perspective, a distinction is made between three key conceptual dimensions of eco-city frameworks and their respective governance function: definitional work, performance assessment, and social learning.

Table 1: Governance dimensions of eco-city frameworks.

\begin{tabular}{|l|l|l|l|}
\hline dimension & function & mode & resonance \\
\hline A-Definitional & $\begin{array}{l}\text { - conceptualising urban } \\
\text { sustainability } \\
\text { - designing contents } \\
\text { - structuring issues }\end{array}$ & $\begin{array}{c}\text { - conceptual- } \\
\text { analytical }\end{array}$ & $\begin{array}{l}\text { - research } \\
\text { community } \\
\text { - planners }\end{array}$ \\
\hline $\begin{array}{l}\text { B-Performance } \\
\text { assessment }\end{array}$ & $\begin{array}{l}\text { - assessing efficiency } \\
\text { - monitoring performance } \\
\text { - evaluating policy } \\
\text { alternatives }\end{array}$ & $\begin{array}{c}\text { - performance } \\
\text { management } \\
\text { - policy-making }\end{array}$ & $\begin{array}{l}\text { - planners } \\
\text { - developers }\end{array}$ \\
\hline $\begin{array}{l}\text { C-Social } \\
\text { learning }\end{array}$ & $\begin{array}{l}\text { - integrating social values } \\
\text { - social learning } \\
\text { - co-producing action }\end{array}$ & $\begin{array}{c}\text { communicative } \\
\text { deliberation }\end{array}$ & $\begin{array}{l}\text { - citizens } \\
\text { - stakeholders } \\
\text { - planners }\end{array}$ \\
\hline
\end{tabular}

The following empirical analysis is based on a sample of nine current eco-city initiatives: three illustrate the use of sets of indicators in relation to 'new build' and 'in-fill' eco-city projects; another three represent the deployment of indicators in city-wide 'retro-fit' initiatives; and a further three relate to eco-city frameworks by international and non-governmental organisations. The nine case studies are drawn from a recent global census, representing a cross-section of the 178 eco-city initiatives identified therein (Joss et al. [6]).

\section{Governance function of indicators: nine eco-cities compared}

Table 2 lists the key governance features and functions related to the use of indicators in the nine analysed eco-city initiatives. Category 1 ('infill'/'new build' eco-cities) includes: North-West Bicester, one of four eco-town projects in England; Tangshan Caofeidian International Eco-City, a $75 \mathrm{~km}^{2}$ new city in North-East China; and Treasure Island, a 450-acre new district of San Francisco. All three are currently at an early development stage. Their plans make explicit use of indicators. NW Bicester bases its master and sustainability plans on the English eco-town Planning Policy Statement (PPS) (Cherwell District Council [7]). The PPS (CLG [8]) includes 16 eco-town standards, of which eight relate to environmental (e.g. carbon neutrality, biodiversity), five economic (e.g. employment, homes) and three social (e.g. healthy lifestyles, community) sustainability aspects. The indicators' function mainly relates to design (dimension A) and social learning (C) through the current first 'exemplar' 


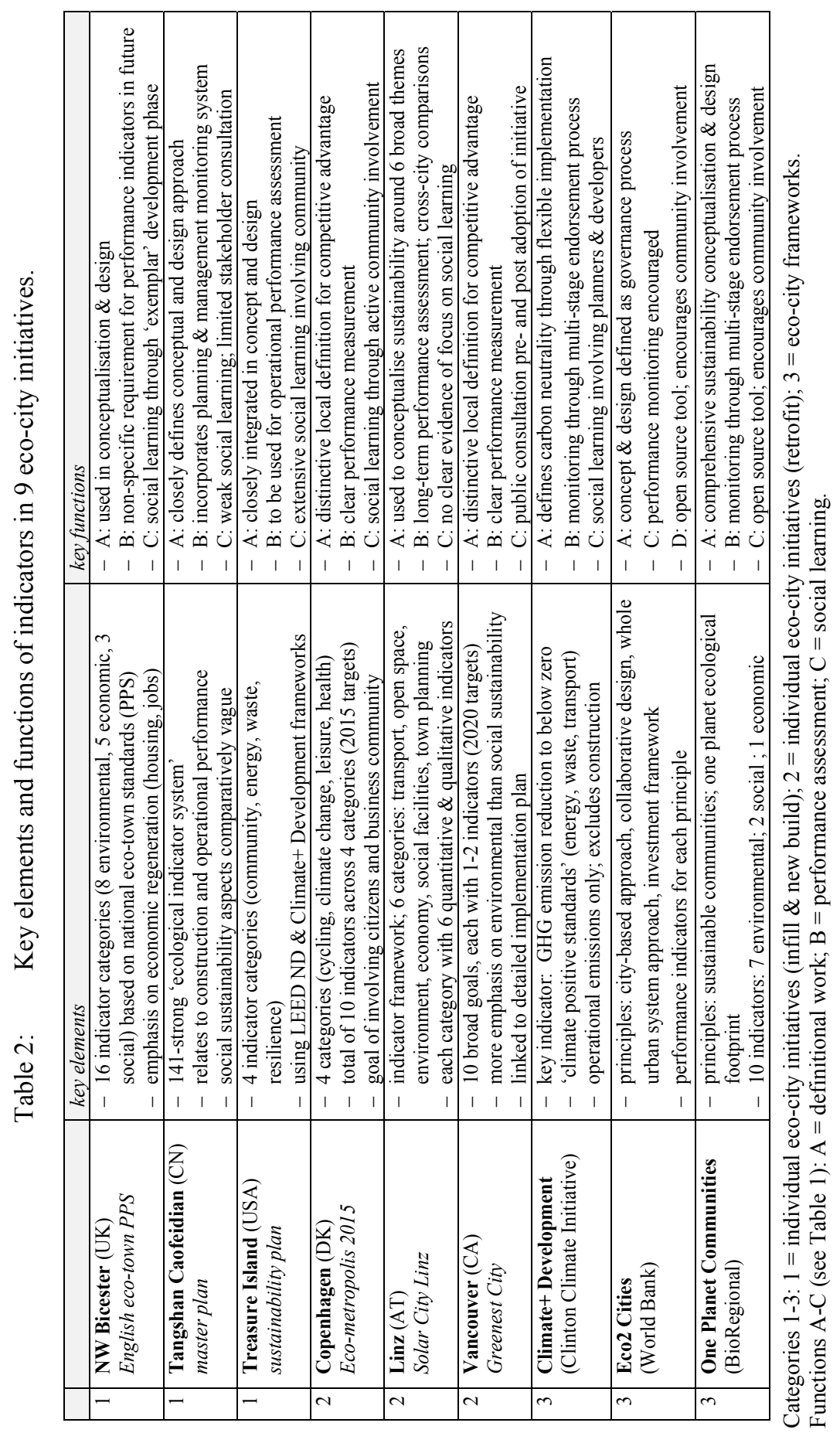


development phase including the first 400 houses and a renewable energy centre. This process will guide subsequent development. (Broader social learning occurred during the government's public consultation on the English eco-town scheme and selection process.) It is as yet unclear how the indicators will be used to measure NW Bicester's operational performance (B) in future.

Tangshan Caofeidian is based on an elaborate 141-strong 'ecological indicator system' (Lin et al. [9]) which emphasises environmental targets; socioeconomic indicators are considerably fewer in number and less specific. The indicator system defines the eco-city concept and design (A) for this brand-new city, and is intended to be used for regular progress monitoring and as a regulatory framework (B) for the various implementation phases. However, it lacks any substantial 'social learning' function (C), with little evidence of public consultation and stakeholder involvement. The Treasure Island sustainability plan (City of San Francisco [10]) has some 20 indicators relating to community (including ca. $25 \%$ social housing), energy (5\% onsite renewable energy generation), waste (full organic waste recycling) and resilience (a target of $\mathrm{CO}_{2}$ neutrality). The indicators' function encompasses all three dimensions (A-C): they were used in the design phase to define the project's urban sustainability features; draw on explicit 'social learning' through extensive public consultation (including a citizens advisory committee and the involvement of a homeless people interest organisation); and are to be used for operational assessment.

Category 2 (whole-city 'retrofit' initiatives) includes the examples of the EcoMetropolis 2015 plan for Danish capital Copenhagen (City of Copenhagen [11]), Solar City Linz in Austria (Linz [12]), and Vancouver (Greenest City initiative) in Canada (City of Vancouver [13]). The indicators associated with all three primarily serve a performance assessment function (B), although they have also been used to define the respective underlying eco-city concepts (A). Concerning the latter, significantly in both the case of Copenhagen and Vancouver the plans perform definitional work without making claims for universal relevance. Rather, they are shaped by locally perceived priorities. Hence, Copenhagen emphasises cycling (three out of ten indicators), while Vancouver focuses on the reduction of its environmental footprint (i.e. relating to public transport, waste, GHG emissions) and the enhancement of 'green' economic competitiveness, which are seen as current weaknesses; a 'liveability' indicator is not included since the city is understood to be performing well already in this respect. In both cases, this local relevance appears to be both a policy strategy to increase 'resonance' among various stakeholders and, at the same time, the outcome of social learning and practice (C). However, while this approach is used by both cities to distinguish themselves as leading green economic centres nationally and internationally, the distinct local indicator definition makes comparison more challenging. In this respect, Linz's approach (Lechner et al. [14]) differs in that it uses a more detailed indicator system - consisting of six key themes, and six indicators for each theme - which is designed to allow for inter-city comparison and to be applicable in other urban settings. Linz thus defines sustainability more generically than the other two; its indicators, however, have a less explicit social learning function. 
The examples given in category 3 are not individual eco-city initiatives, but broader frameworks which include indicators and standards and are managed by international and non-governmental organisations: Climate Positive Development Program devised by the Clinton Climate Initiative [14] and currently involving seventeen member cities around the world; One Planet Communities run by BioRegional [15], a British-based non-governmental organisation, and including four members; and Eco2 Cities, a World Bank initiative [16] with current pilot projects in Indonesia, the Philippines, and Vietnam. While all three schemes use indicators for definitional work (A), their respective emphasis is quite different: Climate+ Development exclusively focuses on $\mathrm{GHG} / \mathrm{CO}_{2}$ reduction to below zero using 'climate positive standards' relating to energy, waste and transport. One Planet Communities is based on a 'one planet ecological footprint' approach and puts emphasis on creating communities where sustainable lifestyles are favoured. In contrast, Eco2 Cities ('ecological cities as economic cities') does not prescribe any sustainabilityrelated indicators per se. Instead, it defines eco-cities mainly in terms of collaborative governance processes. Hence, its framework incorporates indicators relating to such issues as collaborative design, investment mechanisms favouring resilience, and a 'whole urban system' approach.

All three frameworks use indicators in support of performance assessment (B). In the case of both Climate+ Development and One Planet Communities, this is linked to a multi-stage accreditation scheme, from inviting cities to apply for initial candidate status through to awarding certification. Eco2 Cities includes performance indicators linked to each of its eco-city principles, but these serve for guidance, rather than as binding assessment mechanisms. Again, all three schemes incorporate a social learning (C) component: in the case of Climate+ Development this is mainly limited to planners and developers directly involved in the initiatives concerned, whereas both other schemes are designed as open source frameworks available to any interested urban community. Eco2 Cities' guide includes learning materials, such as case studies and design exercises.

\section{Discussion: seven policy challenges}

The comparative analysis of the nine eco-city initiatives confirms the three-fold governance function of indicators centred upon definitional work (conceptualising and designing urban sustainability), performance assessment (monitoring implementation and operation) and social learning (mobilising local knowledge and encouraging local practice). At the same time, the analysis shows considerable variation in the relative emphasis placed on these three functionalities. At present, then, eco-city indicators are defined and applied in various, partially overlapping ways, rather than being uniform tools readily applicable across initiatives. However, as eco-city initiatives increase in number and become more globally spread, the pressure to arrive at more universally comparable and usable approaches will surely increase. Policy learning and transfer across urban and national contexts can be expected to grow as cities and their communities increasingly co-operate to improve urban sustainability 
practice. The experience to date points to several challenges for consolidating eco-city indicator frameworks in the future, as discussed in the following section.

\subsection{The 'triple bottom line' of sustainability}

Since urban sustainability relates to multiple dimensions and complex systems, the substantive definition of indicators requires a comprehensive approach that encompasses various aspects of sustainability and integrates these in a systematic manner. The problématique here is two-fold: first, while in practice environmental aspects of sustainability are often specified in great detail - in terms of both the number of indicators and the specificity of targets entailed social aspects in particular tend to be much less well defined. Second, the precise ways in which individual indicators are inter-related often remains unarticulated: how some may reinforce or counteract others, and what types of direct and indirect impacts may result from their linkages. Thus, it is not uncommon in practice to see atomistic lists of eco-city indicators with a preponderance of environmental criteria alongside a far smaller number of vaguely defined socioeconomic criteria. What is more, typically no clear explanation is given of the mutual interdependence of individual indicators, nor of how different indicators may work in tandem to further the urban sustainability of a given place. Tangshan Caofeidian's indicators arguably fall into this category. In comparison, generic eco-city frameworks, such as One Planet Communities and Eco2 Cities, appear more comprehensive, emphasising integrated urban system approaches.

\subsection{Development life cycle}

Relating indicators to the life cycle of urban sustainability developments presents further integration challenges. In some cases, the main attention tends to be on the design side of an urban sustainability development and less on performance monitoring (for example, the LEED indicator/rating system). While the design stage obviously provides a critical opportunity to incorporate urban sustainability targets and specify and assess corresponding indicators, later stages in a development's life cycle are pivotal, too: both the implementation and in-use phases co-determine how successfully the indicator targets are met. Poor implementation practice due to, say, lack of training or untested technology, and lack of adherence by users may render urban sustainability features partially defunct and lead to underperformance in comparison with the original indicator targets. Therefore, some eco-city frameworks (including Climate+ Development Program and One Plant Communities) insist on staged assessment processes.

Another life-cycle consideration is whether indicators relate only to a development's operation, or also encompass its construction and later-life refurbishment. Climate+ Development excludes construction-related GHG emissions in the formal accreditation process, although it requires developers to build these into their development plans. Similarly, Tangshan Caofeidian's indicator system mainly looks to the future city's operation, while remaining silent about sustainability performance during construction. It is difficult to make 
the case that an eco-city framework is comprehensive if it excludes indicators and related assessments concerning both the building and later-life phases.

\subsection{City-region dimensions}

As has long been recognised, the sustainability of an urban setting does not only relate to the urban area itself, but also to the relationship with its surrounding hinterland. Even if a city's sustainability can be enhanced, the resource-intensive nature of the city almost always means that it relies on its hinterland to provide resources and absorb its waste. While this has obvious relevance for environmental sustainability, it also applies to economic and social sustainability issues: in considering, for example, where to encourage business growth, a local authority will take into account the context of the development opportunities of a geographical area extending beyond its own boundaries. It is for this reason that there is a growing interest in city-regions. Eco-city indicators should, therefore, be defined in a way that takes into account wider regional dimensions and interests. This requires an assessment of how sustainability targets for a particular urban setting relate to the wider (regional) policy, what the likely impact of these targets are on the surrounding areas, and how integration across scales can be enhanced.

\subsection{Policy and regulatory integration}

Integration should also occur in relation to wider policy and regulation. Aligning the contents of indicators with relevant policy - for example, concerning $\mathrm{CO}_{2} / \mathrm{GHG}$ reduction - helps ensure that urban sustainability projects reflect policy strategies and targets. Among the cases analysed here, this goal is most comprehensively achieved in Copenhagen's Eco-Metropolis 2015 and Vancouver's Greenest City. Similarly, the indicators in Treasure Island's sustainability plan draw on, and are defined to comply with, several city- and state-wide policies (e.g. the city's sustainability and health plans). Furthermore, Treasure Island's indicators are defined so as to allow for future adjustment in response to policy changes - an important consideration, given that substantial urban sustainability initiatives typically take a couple of decades from inception to full implementation, during which time policy is likely to evolve either in response to new scientific evidence (for example, predicted sea level rises) or changed political priorities. Aligning indicators and standards with wider policy frameworks, therefore, provides planners and developers with certainty and legitimacy. There is often scope, however, to strengthen the link between indicators and policy, by tying the use of indicators to statutory implementation mechanisms. If indicators and standards are used as part of a statutory process for example, to approve development plans and issue development control permits - this provides further certainty and monitoring capability for both developers and policy-makers. Where policy and regulatory frameworks are weak or lag behind urban sustainability innovation, indicators can be useful beyond the projects for which they are applied by contributing applied knowledge and analysis to the development of wider policy. 


\subsection{Marketability}

The use of indicators and standards in the design, planning and implementation of urban sustainability initiatives can come at extra costs to developers: it requires additional resources, from the expense of developing indicators and complying with standards, to the costs associated with delivering enhanced sustainability features. As a quid pro quo, there have to be incentives - namely, faster development processes and reduced (financial) risk: in return for incorporating indicators and complying with standards, the process of obtaining approval for a project's development plan should be more efficient and assured. Here, accreditation schemes - such as Climate+ Development and One Planet Communities - offer tailor-made services and products; they define, each in their own particular way, indicators and standards that can be used in the design and implementation of a project. If, as a result, the project is deemed to comply with the scheme's criteria, membership is granted. Membership acts - like the 'kitemark' - as a certification mark standing for a particular concept, quality and standard of urban sustainability, and improving marketability. However, unless an accreditation scheme is recognised by officialdom, membership of it does not automatically confer more efficient and assured development project approval. The recent growth in the number of urban sustainability accreditation schemes, and their lack of direct comparability, poses a challenge for those trying to understand which scheme is best suited for what development. In future, the various schemes might reasonably be expected to converge, resulting in an internationally recognised certification scheme.

\subsection{Accountability of practice}

Central to indicators and standards is the function of quantification: capturing, measuring and monitoring urban sustainability in the form of quantifiable data. As a 'technology of visibility', they serve as "tools that communities [of experts, planners, citizens etc] can use to see things that they have not seen before" (Miller [2] 425). This function requires accountability: information needs to be available about the type of data gathered, who is in charge of the measuring and monitoring process, and how the resulting knowledge is used. If it is unclear how indicators and standards have been arrived at and applied, then their validity and accuracy cannot be scrutinised, and they may not be replicable elsewhere. This, in turn, impedes wider social learning about urban sustainability, and may undermine the legitimacy of practical initiatives. Given the pivotal importance of accountable governance for achieving effective sustainable development, transparency is paramount to the development and use of indicators and standards. This is particularly so currently, when much learning about the definition and implementation of urban sustainability is still ongoing, and when - in the absence of globally established standards - there is a growing array of competing indicator frameworks and accreditation schemes.

\subsection{Community involvement}

Arguments for the involvement of non-expert communities in the development and application of indicators and standards have been made on the grounds of 
their socio-cultural base, as well as their potential communicative function (Hezri and Dovers [2]). These arguments acknowledge that our understanding of urban sustainability is not exclusively derived from the environmental sciences, but is co-determined by socio-cultural concepts and practices. Thus, mobilising and integrating various relevant (technical and non-technical) knowledge sources enhances the definitional work involved in indicators. The substantive input by various users also helps increase their sense of ownership and, thus, strengthens the resonance of urban sustainability among users. As Hezri and Dovers [2, p 95] argued, when developed and used jointly across networks of actors, indicators can take on a communicative function which generates shared information and meaning. In turn, the resulting knowledge can become embedded in the network actors' institutions and practices and, consequently, lead to changes of behaviour and action.

\section{Conclusions: towards international standards}

The growth of practical 'eco-city' (and similarly labelled) initiatives globally in response to climate change and urbanisation concerns has turned the quest for urban sustainability indicators and standards from a predominantly theoretical undertaking by academic researchers into an increasingly urgent priority for policy-makers, planners and developers. Yet, as this paper shows, figuring out conceptually as well as methodologically what are the key elements and functions of urban sustainability indicators is far from being a completed task. What is more, empirical analysis - as illustrated by the nine eco-city initiatives discussed in this study - reveals significant diversity of practice.

It may, therefore, be unrealistic to expect international eco-city standards to be developed and adopted any time soon, although notably several international organisations and initiatives are currently vying for a leading role in this respect. While a strong case for international indicators and standards can certainly be made against the background of growing pressure to render urban centres and urbanisation more sustainable, the evident tension between universal standards and local factors and contexts may realistically not be easily resolved. However, this does not mean that there is not an important agenda to generate analytical data, in order to consolidate our understanding of the functional role of indicators and consider the challenges associated with their conceptual development and practical implementation. To this end, it is essential to encourage more international, comparative analysis of the use of urban sustainability indicators in diverse 'eco-city' contexts. In turn, this will help inform and facilitate policy transfer, practical co-operation and social learning at global level.

\section{Acknowledgement}

This research was supported with funding from the Nirman Foundation (Alexandria, USA). Simon Joss is the principal author of this article. 


\section{References}

[1] Joss, S. Eco-cities: the mainstreaming of urban sustainability; key characteristics and driving factors. International Journal of Sustainable Development and Planning, 6(3), pp. 268-285, 2011.

[2] Hezri, A.A. \& Dovers, S.R. Sustainability indicators, policy and governance: issues for ecological economics. Ecological Economics, 60(1), pp. 86-99, 2006.

[3] Keirstead, J. \& Leach, M. Bridging the gaps between theory and practice: a service niche approach to urban sustainability indicators. Sustainable Development, 16(5), pp. 329-340, 2008.

[4] Miller, C.A. New civic epistemologies of quantification: making sense of indicators of local and global sustainability. Science, Technology \& Human Values, 30(3), pp. 403-432, 2005.

[5] Munier, N. Methodology to select a set of urban sustainability indicators to measure the state of the city, and performance assessment. Ecological Indicators, 11(5), pp. 1020-1026, 2011.

[6] Joss, S., Tomozeiu, D. \& Cowley, R. Eco-cities: a global survey 2011. University of Westminster, www.westminster.ac.uk/ecocities

[7] Cherwell District Council, www.cherwell.gov.uk/index.cfm?articleid $=4513$

[8] Communities and Local Government. Planning Policy Statement: ecotowns: A supplement to Planning Policy Statement 1. London: Communities and Local Government Publications, 2009.

[9] Lin, P, Bi, B., Dong, Z. \& Zhang, R. Caofeidian eco-city development practice. [Translated] 2010 Development Report on China's Low-Carbon Eco-Cities. Chinese Society for Urban Studies. Beijing: China Architecture and Building Press, pp. 425-430, 2010.

[10] City of San Francisco. Treasure Island/Yerba Buena Island Sustainability Plan (2011), www.sftreasureisland.org

[11] City of Copenhagen. Eco-Metropolis: Our Vision for Copenhagen 2015. http://kk.sites.itera.dk/apps/kk publikationer/pdf/674_CFbnhMePZr.pdf

[12] Linz. Solarcity Pichling: Evaluation. http://www.linz.at/english/life 3203.asp

[13] City of Vancouver Greenest City 2020 Action Plan. http://vancouver.ca/ctyclerk/cclerk/20110712/documents/rr1.pdf

[14] Lechner, R., Koblmüller, M. \& Bruck, M. Checkliste für Städtebauliche Wettbewerbe auf Basis des Bewertungstools „LES! Linz entwickelt Stadt!“ www.ecology.at/files/berichte/E07.760-2.pdf

[15] Clinton Climate Initiative, www.clintonfoundation.org/what-we-do/clintonclimate-initiative/cities/climate-positive

[16] BioRegional, www.oneplanetcommunities.org/

[17] World Bank, http://web.worldbank.org/urban 